\title{
Investigation of Split Injection in a Single Cylinder Optical Diesel Engine
}

\author{
Alvaro Diez, Hua Zhao \\ Brunel University
}

\begin{abstract}
Over the last decade, the diesel engine has made dramatic progress in its performance and market penetration. However, in order to meet future emissions legislations, Nitrogen Oxides (NOx) and particulate matters' (PM) emissions will need to be reduced simultaneously. Nowadays researchers are focused on different combustion modes which can have a great potential for both low soot and low NOx. In order to achieve this, different injection strategies have been investigated.
\end{abstract}

This study investigates the effects of split injection strategies with high levels of Exhaust Gas Recirculation (EGR) on combustion performance and emissions in a single cylinder direct injection optical diesel engine. The investigation is focused on the effects of injection timing of split injection strategies.

A Ricardo Hydra single cylinder optical engine was used in which conventional experimental methods like cylinder pressure data, heat release analysis and exhaust emissions analysis were applied. Optical techniques like direct spray and combustion visualization were applied by means of a high speed imaging system with a copper vapor laser illumination system and a high-speed two-color system was applied to obtain in-cylinder diesel combustion temperature and soot measurements distributions.

\section{INTRODUCTION}

Diesel engines have become in recent years a very important part of the automotive industry, representing nowadays a very important part of the market of car sales in Europe. But, due to the more and more stringent regulations on vehicle emissions to reduce pollutants emissions in vehicles and in particular Nitrogen Oxides (NOx) and soot emissions in diesel engines, automotive research has been focused on reducing these pollutants emissions, since they represent the most important emissions in conventional diesel combustion.

The pollutant formation in diesel engines has been extensively studied and is well understood. Particulate matters in the exhaust consist mainly of soot, its formation occurs from the combustion of a richer than stoichiometric mixture. NOx formation is associated to the combustion at high temperatures with an excess of oxygen and hydrocarbons that can be found in the diesel emission consisting of decomposed fuel molecules or intermediate compounds, are related to very lean regions, where the excess of air prevents the combustion from initiating or propagating.

The invention of the common rail (CR) fuel injection equipment (FIE) in diesel engines has led to one of the biggest improvements in diesel engines. The flexibility in the injection system has made possible for researchers to investigate combustion modes different from the conventional diesel combustion. Some of these modes are homogeneous charge compression ignition (HCCI) combustion [1], premixed charge compression ignition 
(PCCI) [2] or low temperature combustion (LTC) [3] to achieve a diesel combustion reducing the NOx and soot emissions simultaneously. In order to achieve this, many different injection strategies have been investigated in the recent years. Among these studies, the first investigations were related to pilot and main injection [4-7], they were focused on pilot plus main injection or split injection with a fuel distribution $50 \% / 50 \%$. They found that by means of a pilot injection, the ignition delay was reduced and as a result the heat release rate peak was reduced. Peak gas temperature was thus lower, reducing the NOx emissions. Although the mixing controlled phase was increased, the soot emissions were not increased as split injection enhanced better mixing and air utilization. Subsequent to the studies on the pilot plus main and the split injections, investigations on split injection including strategies with a post injection have been conducted $[8,9]$. They found that when there was post injection, or split injection with the second injection quantity lower than the first injection quantity, there was a reduction of soot emissions. This was mainly because the post injection increased the combustion temperature during the diffusion phase and enhanced soot oxidation. In addition, recent studies have explored the combination of different factors such as split injection with EGR [10, 11]. Montgomery and Reitz [10] investigated split injection in a conventional heavy duty diesel engine with EGR levels between 10 to $25 \%$. Their investigations showed that it was possible to reduced NOx and soot emissions simultaneously where the NOx reduction was achieved by the presence of EGR and the soot reduction was enhanced by split injection due to improved the mixing process. In order to understand the mixing process, Zhang et al. [12, 13] carried out a series of investigations on the mixing process in diesel engines by means of laser absorption scattering (LAS) for the spray visualization in a constant volume chamber. They compared the mixing process of single injection with split at 75\%/25\%, 50\%/50\% and 25\%/75\% injection rates, finding that the 75/25 strategy showed the best improvement regarding soot emissions for their engine conditions. As injection systems become more flexible, investigations have been extended to triple injection strategies $[11,14]$ or pilot + main + post injection strategies $[15,16]$. In these investigations they found that increasing the time between pilot and main injection would decrease NOx emissions. However, after a certain dwell angle the soot emissions would increase. As stated previously the addition of the post injection would reduce soot but having the drawback of increased fuel consumption and $\mathrm{HC}$ emissions.

More recently, injection strategies have been investigated with up to 4 or 5 injections [17-19]. These researchers have focused their studies in order to achieve new combustion models like HCCI or LTC to reduce soot and NOx simultaneously.

Although split injection strategies have been investigated previously, limited in-cylinder investigations have been conducted regarding split injection with high levels of EGR As stated previously, EGR has been proven responsible for the NOx reduction in diesel engines. In addition, split injection strategies, where the first injection quantity is higher than the second injection, have shown a potential in reducing the soot emissions because of the improvement of the mixing process. Furthermore, most of the investigations available are simulation or experimental work based on conventional engines and few investigations have been focused on split injection strategies within an engine with optical access. This study attempts to resolve this question presenting an investigation of split injection strategies with high levels of EGR from an optical approach involving the high speed direct visualization and the two-color method. 


\section{EXPERIMENTAL SETUP}

\section{OPTICAL RESEARCH ENGINE}

All experimental testing in this study was completed on a single cylinder Ricardo Hydra engine, designed to be representative of a typical modern high-speed direct injection (HSDI) diesel engine. The engine specifications are detailed in Table 1.

\section{Table 1 Engine Specifications}

\begin{tabular}{ll}
\hline Ricardo Hydra Single-Cylinder Engine & \\
\hline Bore & $86 \mathrm{~mm}$ \\
Stroke & $86 \mathrm{~mm}$ \\
Swept Volume & $499 \mathrm{~cm} 3$ \\
Compression Ratio & $16.0: 1$ \\
Piston Bowl Diameter/Depth & $43.4 / 11.6 \mathrm{~mm}$, Cylinder Shaped \\
Swirl Ratio & 1.4 \\
Engine Speed for Testing & $2000 \mathrm{rpm}$ \\
\hline
\end{tabular}

The engine consists of a Ricardo Hydra crankcase, an extended cylinder block and a cylinder head platform. The cylinder block has an upper and lower part that allows space to mount an extended piston and also features three cylinder wall cut-outs where glass windows can be fitted to gain optical access through the side. The engine is mounted with a standard production cylinder head and a common-rail fuel injection system. The cylinder head is from a production Ford 2.0 litre ZSD 420 Duratorq turbocharged engine. The cylinder head includes 4 valves, a centrally located injector and a glow plug. For this study, as the glow plug is not required, a Kistler 6125 piezoelectric pressure transducer for measuring in-cylinder pressure is positioned instead.

The fuel system consists of a $12 \mathrm{~V}$ low pressure pump that supplies fuel from the tank through a filter and regulator to the high pressure pump. The high pressure pump is a production Bosch 1st generation common rail pump driven by the engine. The fuel is supplied to a Delphi HP common rail through a single thick-wall steel pipe. The common rail is fitted with a Delphi rail pressure sensor, the signal of which is sent to the ECU to control the injection pressure. The common rail has four outlets, three of which are blanked off and the remaining one connects the rail with the injector. The injector used for this study was a Delphi injector. Table 2 shows the specification of the injector.

\section{Table 2 Fuel injector specifications}

\begin{tabular}{ll}
\hline Delphi Wide Angle Injector \\
\hline Number of Holes & 6 \\
Hole Size & $0.123 \mathrm{~mm}$ \\
Cone Angle & $155^{\circ}$ \\
Flow rate & $557 \mathrm{cc} / \mathrm{min}$ \\
Type & Microsac \\
\hline
\end{tabular}


The injection system is controlled by an ECU supplied by EmTroniX. This ECU is operated with a software called EC-Lab installed in a PC. The ECU receives input signals from the shaft encoder and rail pressure. Via the EC-Lab, injection pressure, number of injections, timing and quantity can be adjusted.

\section{CONVENTIONAL TECHNIQUES}

For the strategies analyzed, cylinder pressure data was recorded from which heat release rate was calculated. Emissions and soot tests were also carried out to assess the effect on performance and emissions of different injection strategies. The exhaust emissions measurements of $\mathrm{CO}, \mathrm{CO} 2, \mathrm{O} 2$, uHC, NO and NOx were taken by means of a Horiba MEXA-7170DEGR analyzer and soot emissions were measured using an AVL 415 smoke meter.

\section{OPTICAL TECHNIQUES}

The optical techniques applied in this study consist of high speed combustion imaging and the two-color method developed for the use of high speed video cameras.

The two-color method is based on the measurement of the soot radiation emitted during combustion at two different wavelengths. The soot concentration is normally given by the $\mathrm{KL}$ or soot loading factor, in which $\mathrm{K}$ is an absorption coefficient proportional to the density of soot and $\mathrm{L}$ is the geometric flame thickness along the optical axis of the detection system.

The two-color method is a well-know technique for the estimation of flame temperature and soot concentration. It is a technique that provides information of the combustion characteristics with a relatively easy setup and calibration procedures. However there are several sources of uncertainty or errors like soot deposition on windows, wall reflections or related to the measuring systems such us noise, the use of bandpass filters, etc. Therefore results obtained by this method should be processed and analyzed properly. For instance, for soot concentrations measurements, the error could be of 10\% [20-22] or even higher depending on wavelengths elections, though the flame temperature values are less affected and rather accurate.

\section{$\underline{\text { Combustion Imaging }}$}

High Speed Imaging was used to record videos of the combustion and also the fuel spray during the injection period. In order to visualize the injection spray a CU15 Oxford Lasers copper vapor laser was used. The high speed video camera used is a NAC Memrecam FX6000, equipped with a high speed colour CMOS sensor. The frame rate used in this study was 10,000 frames per second. The image resolution was 512 x 248 pixels. A Nikon 50mm f.1.4 lens was mounted.

\section{$\underline{\text { Two-Color Method }}$}

The optical set-up consists of a high speed camera NAC Memrecam FX6000, a DRS intensifier ILS-3-11 and a standard Nikon 60mm f2.8 lens. In front of the lenses, a mounting was created to hold an image doubler where two half-circumference bandpass filters at $550 \mathrm{~nm}$ and $750 \mathrm{~nm}$ were fitted. Two neutral density filters were placed in front of the $550 \mathrm{~nm}$ bandpass filter so that the radiation intensities at 550nm and 750nm were approximately of the same range. 


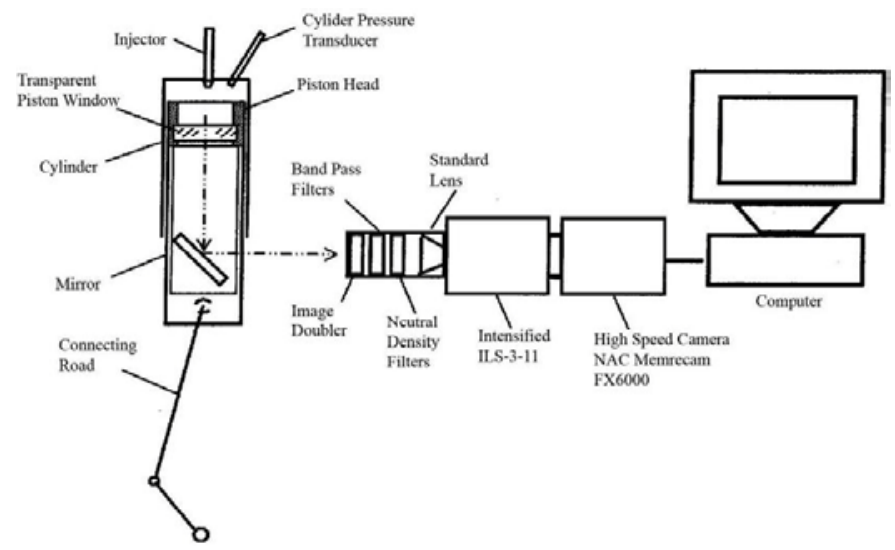

Figure 1 Schematic of the Two-Color Experimental Setup

\section{OPERATING CONDITIONS}

The different split injection strategies were investigated at a part load operating condition at 2000rpm with high EGR levels. The percentage of EGR was set to $60 \%$ for all the experiments by replacing part of the air with N2 gas. Experiment A1 was the reference condition. In order to achieve the in-cylinder conditions (motoring peak pressure and temperature of 33 bar and $715 \mathrm{~K}$, calculated from the cylinder pressure data) and ignition delay (ID=16 CA) in the single cylinder optical engine as the multi-cylinder engine, the boost pressure was controlled and the intake temperature heated up to $140^{\circ} \mathrm{C}$. The test conditions for this study are detailed in Table 3 .

\section{Table 1 Engine operating conditions}

\begin{tabular}{ll}
\hline Test Conditions & \\
\hline Engine Speed & $2000 \mathrm{rpm}$ \\
& $140^{\circ} \mathrm{C}$ \\
Intake Air & $0.5 \mathrm{bar}$ boost \\
EGR & $60 \%(\mathrm{~N} 2)$ \\
Fuel & $49.1 \mathrm{CN}$ Diesel \\
Fuelling & $9.25 \mathrm{~mm} 3$ total (70\%/30\%) \\
Injection duration & $4.5^{\circ} \mathrm{CA} \mathrm{1st} \mathrm{injection}$ \\
Injection Pressure & $3.8^{\circ} \mathrm{CA} 2$ 2nd injection \\
\hline
\end{tabular}

An $8^{\circ} \mathrm{CA}$ dwell-angle split injection strategy was investigated at 1200 bar injection pressure. Five injection timings were investigated for this strategy forming the base matrix of this study, as shown in Table 4.

Table 2 Tests conditions

\begin{tabular}{|l|l|l|l|}
\hline Dwell & \multirow{2}{*}{$\begin{array}{l}\text { Split Injection } \\
\text { Angle } \\
\text { (CA) }\end{array}$} & $\begin{array}{l}\text { Test } \\
\text { Number }\end{array}$ & \multicolumn{2}{|l|}{ (CA BTDC) } \\
\cline { 3 - 4 } & & 1st SOI & 2nd SOI \\
\hline
\end{tabular}

Page 5 of 16 


\begin{tabular}{|l|l|l|l|}
\hline \multirow{5}{*}{8} & A1 & 19 & 11 \\
\cline { 2 - 4 } & A2 & 17 & 9 \\
\cline { 2 - 4 } & A3 & 15 & 7 \\
\cline { 2 - 4 } & A4 & 13 & 5 \\
\cline { 2 - 4 } & A5 & 11 & 3 \\
\hline
\end{tabular}

\section{RESULTS AND DISCUSSIONS}

Figure 2 illustrates the values regarding engine output as well as the NOx and soot emissions for all injection timings within the strategy studied.

\section{Engine Output and Emissions}

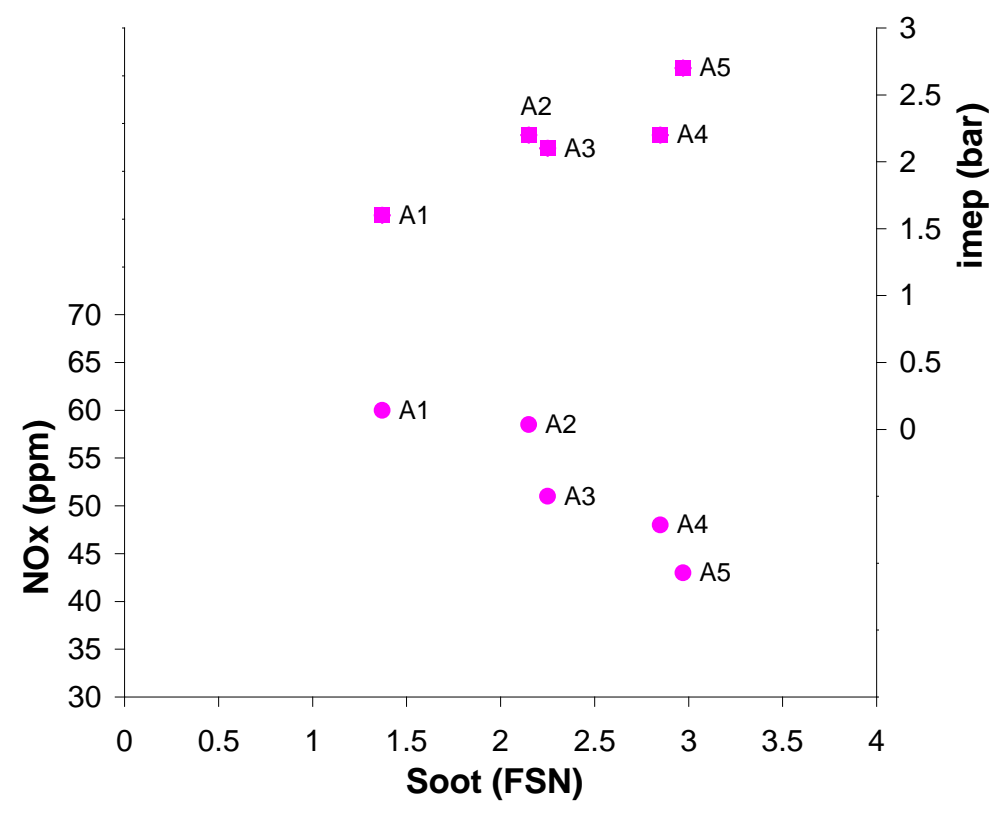

Figure 2 Engine output and emissions values for the five injection timings of Strategy A 


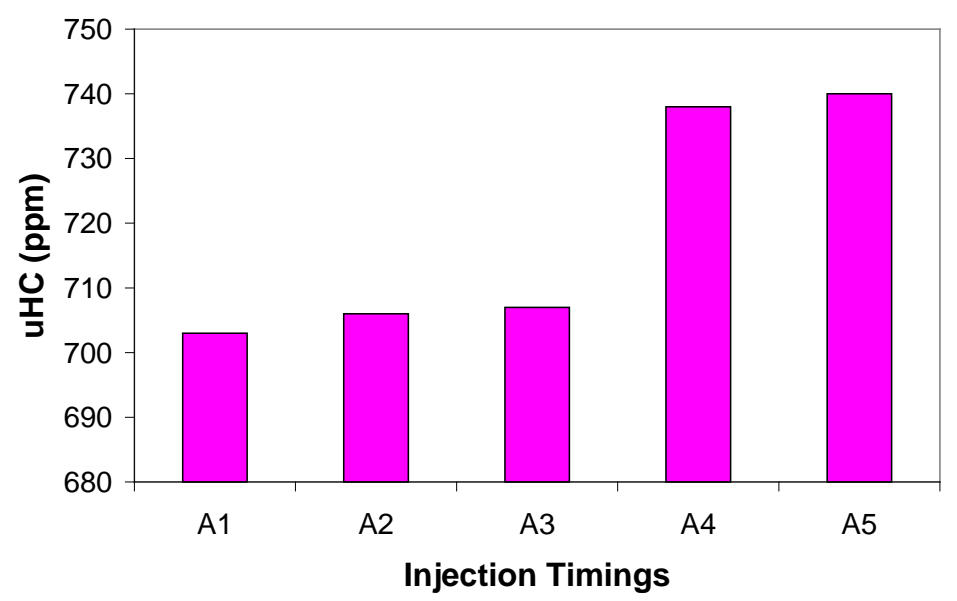

Figure 3 uHC emissions for the five injection timings of Strategy A

\section{STRATEGY A}

Figure 4 shows the cylinder pressure values and the heat release rates for the five experiments in strategy A. Looking at the cylinder pressure values, it can be seen that as the injection timing is retarded the cylinder peak values are lower, but the values over the expansion stroke are higher giving higher IMEP values as seen in Figure 2. The heat release rate curves show a gradual decrease until fuel injection takes place; this is probably due to blow-by, as some gas can flow past the piston rings or between the graphite gasket fitted between the window and the upper piston. From the curves it can be seen that the injection timings A1 and A2 show a clearly premixed combustion phase following the diffusion combustion phase. As injection timing is retarded, the ignition delay is shorter and therefore there is less fuel ready to burn in premixed combustion and more diffusion combustion appears; For instance, from the cumulative heat release data, $50 \%$ of fuel is burned in 8.6 CA ASOI for A1 compared to 12.2 CA ASOI for A5.

Combustion imaging and the two-color method for flame temperature and soot concentration measurements were carried out for experiments A1, A3 and A5. 


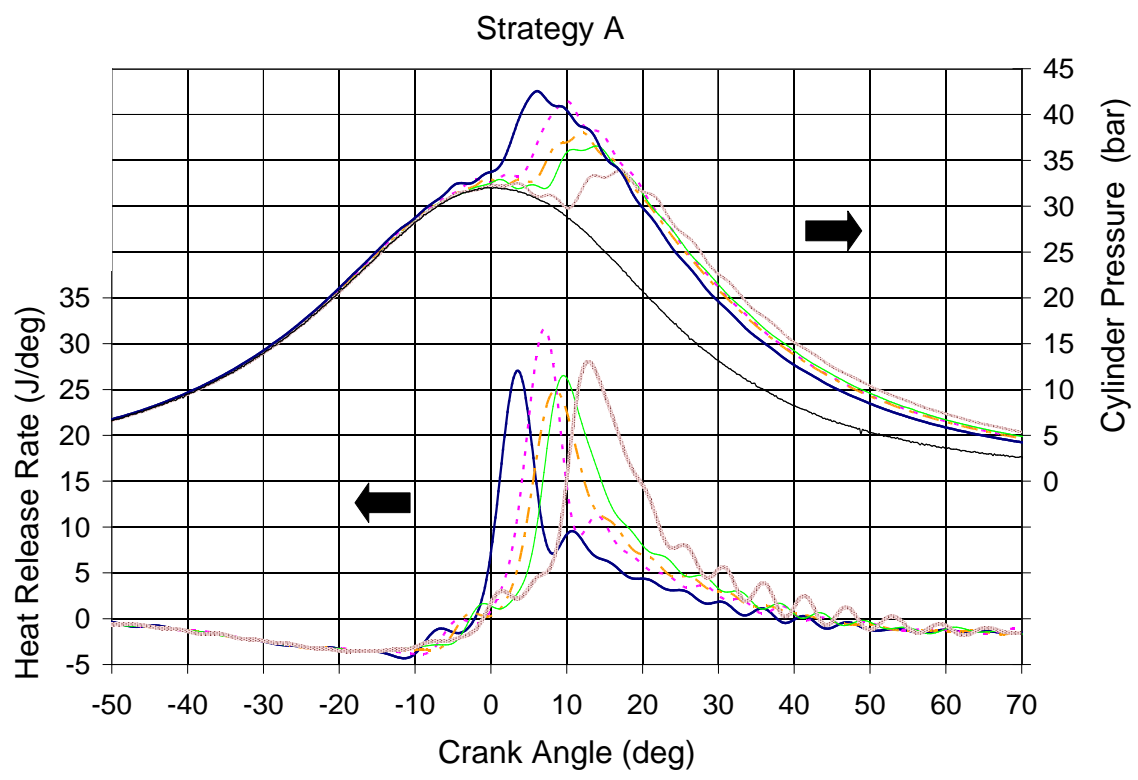

Figure 4 Cylinder Pressure and Heat Release Rate for Strategy A

\section{$\underline{\text { Injection Timing A1 }}$}

Figure 5 shows the combustion images sequence for injection timing A1. The first flames appear at 3.6 BTDC, corresponding with the heat release rate data. It can be seen that four ignition sites appear slightly downstream of the spray in the direction of swirl. At TDC combustion has expanded to larger regions, one at the top and the other at the bottom. The color difference between the combustion regions can be related to the combustion process. For example, at the top of the image, less luminous combustion indicates a more premixed combustion, while at the bottom of the image; the high luminosity is caused by the burning of carbon particles which is more typical of diffusion combustion. In the next frames, it can be seen that the combustion regions slightly spread following the in-cylinder swirl motion and the burning regions become more luminous due to the soot radiation characteristic of diffusion combustion.
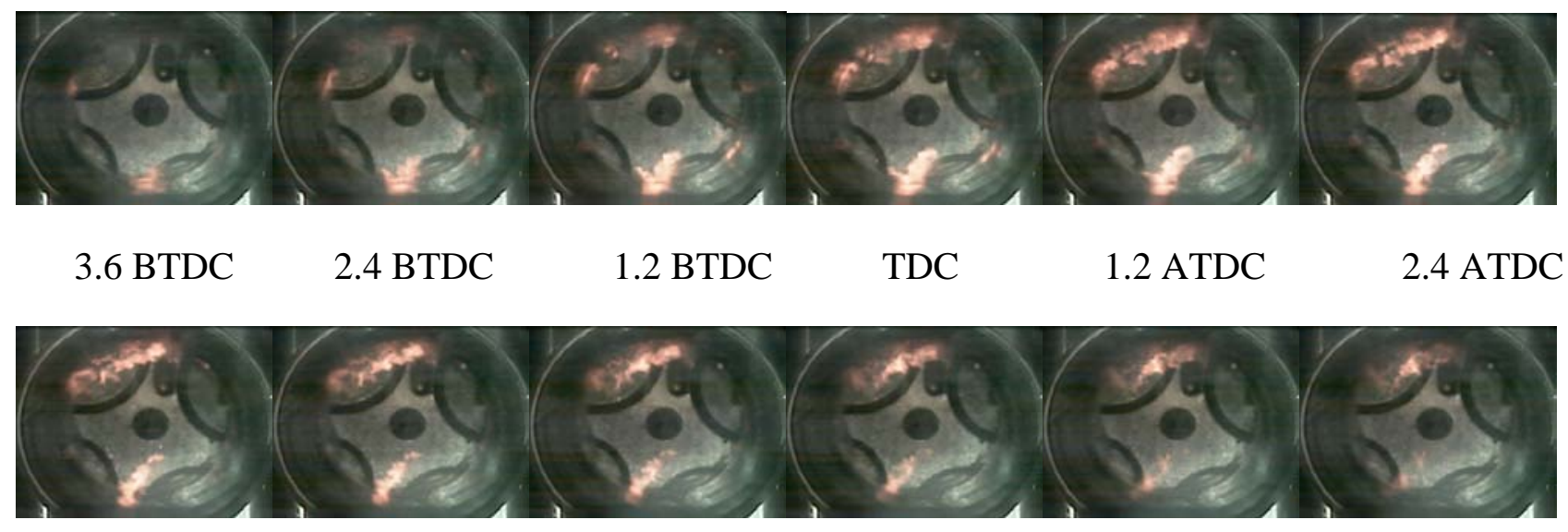
3.6 ATDC
4.8 ATDC
6.0 ATDC
7.2 ATDC
8.4 ATDC
9.6 ATDC

Page 8 of 16 


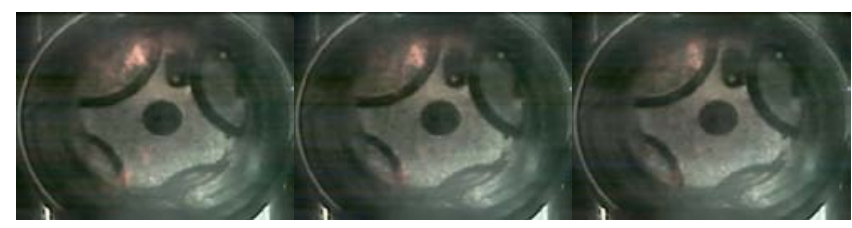

\subsection{ATDC 12.0 ATDC 13.2 ATDC}

Figure 5 Combustion Imaging for A1, frames from 3.6 BTDC to 13.2 ATDC

Figures 6 and 7 present the images sequence for the flame temperature and the soot concentration given by the KL factor for A1 injection timing. The first and most visible two-color images start to appear around TDC. In the temperature images, it can be seen that there are four main focal points where the flame temperature is high, reaching $2500 \mathrm{~K}$. Looking at the KL factor image at TDC, it can be noticed that soot is produced at this stage but at very low concentrations. This is typical of premixed combustion where higher temperatures are produced and small soot particles form at the leading edge of the flame front. Up to $7.2^{\circ}$ ATDC, the flame temperature at some specific points remains quite high. During the premixed combustion, NOx is produced at high temperature regions, therefore it could be expected some NOx formation in the exhaust emissions. Figure 2 shows the emissions values for strategy A. NOx emissions are very low compared to conventional diesel combustion with a single injection. However, experiment A1 indicates a relatively high value with $60 \mathrm{ppm}$ at the exhaust. The next frames show the decrease of the flame temperature and a small increase of local soot concentration, shown by the KL factor images. This can be due to a lower oxidation rate as flame temperature decreases. For this particular strategy the value of smoke given by FSN was 1.37.

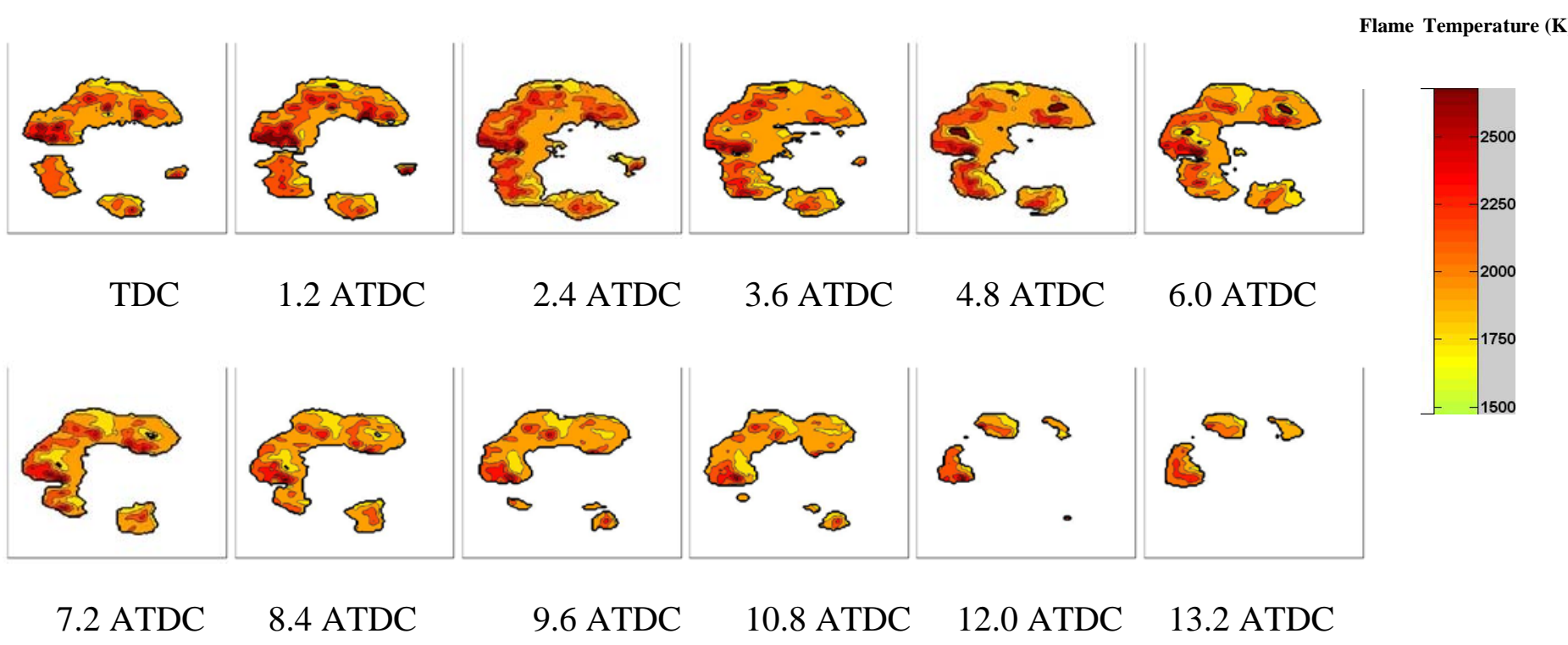

Figure 6 Flame Temperature for A1, frames from TDC to 13.2 CA ATDC 


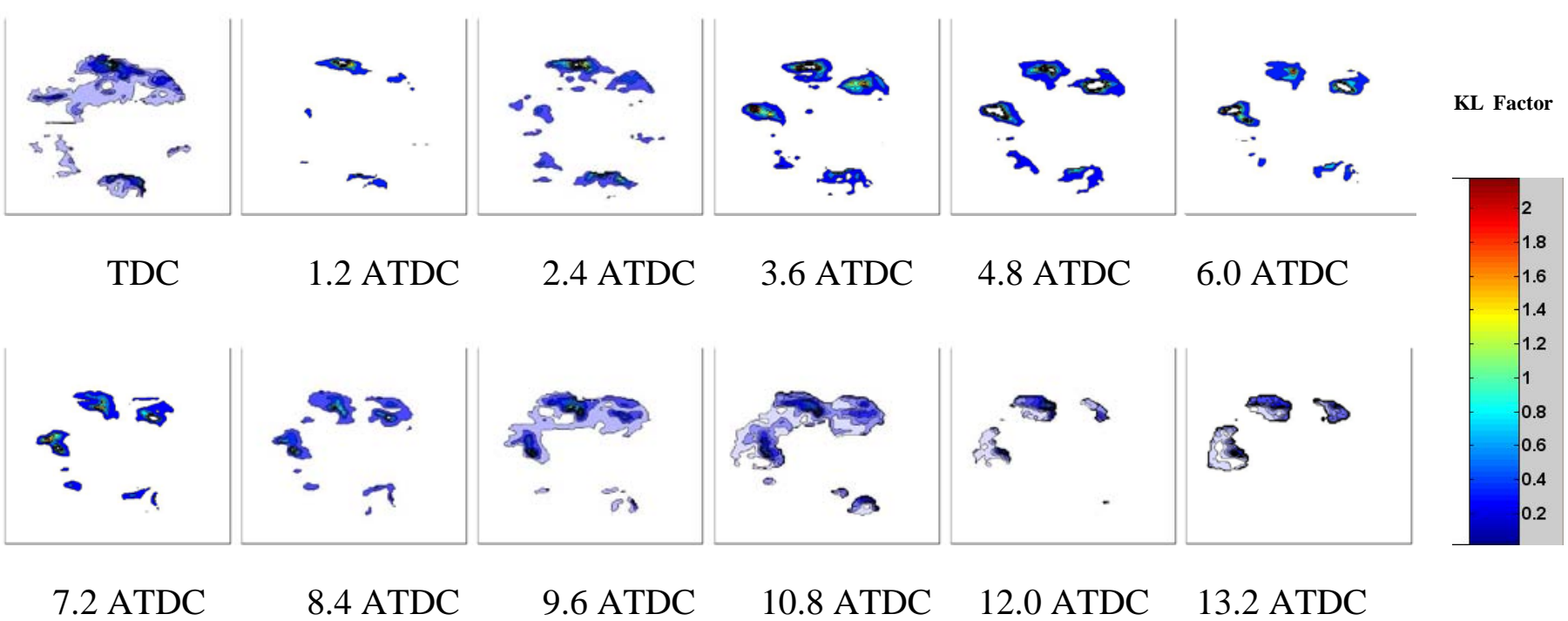

Figure 7 KL Factor for A1, frames from TDC to 13.2 CA ATDC

Injection Timing A3

Figure 8 shows the combustion imaging for experiment A3. This strategy produced an IMEP 30\% higher than A1, with lower NOx emissions. The first visible flames appear at TDC in the form of premixed combustion. These ignition spots appear slightly downstream of the spray in the direction of the swirl. By 3.6 ATDC five different spots can be easily identified (compared to four combustion regions in A1). From frame 4.8 ATDC, the luminosity of the flames indicates diffusion combustion with the formation of soot.

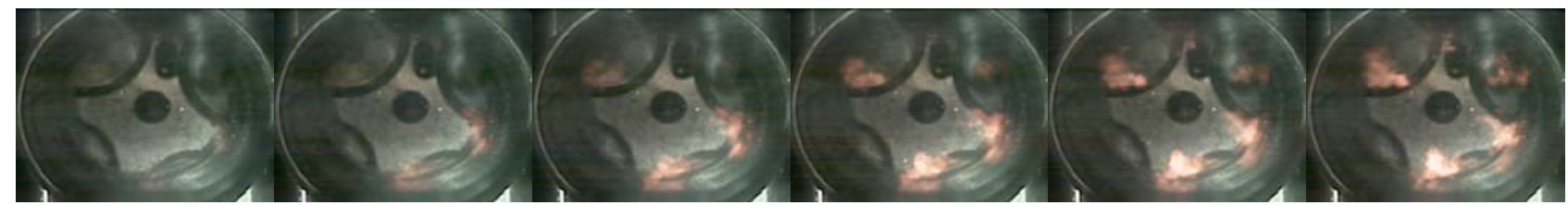

TDC

1.2 ATDC

2.4 ATDC

3.6 ATDC

4.8 ATDC

6.0 ATDC

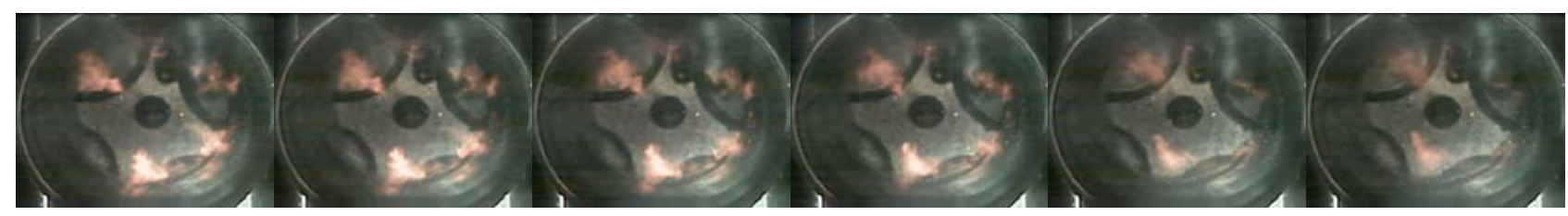

7.2 ATDC 8.4 ATDC

9.6 ATDC

10.8 ATDC

12.0 ATDC

13.2 ATDC

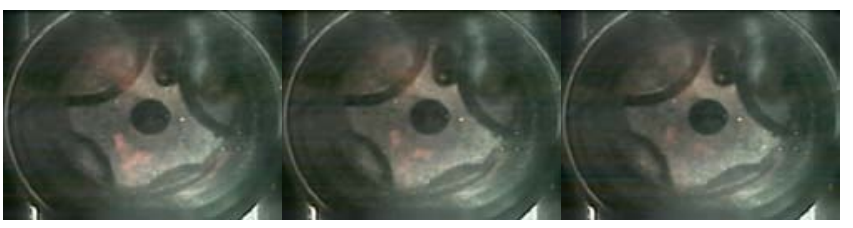

14.4 ATDC 15.6 ATDC $\quad 16.8$ ATDC

Page 10 of 16 
Figure 8 Combustion Imaging for A3, frames from TDC to 16.8 ATDC

Figures 9 and 10 show present the images sequence for the flame temperature and the soot concentration given by the KL factor for A3 injection timing As seen in the combustion sequence from Figure 8, the first flames spots that appear at TDC have little luminosity. Hence the first frame for flame temperature and KL factor shows a very small flame and the production of soot is very low. From frame 2.4 ATDC, it can be seen that combustion takes place consistently within the cylinder. The main flames have a temperature about $2500 \mathrm{~K}$, but rapidly decrease from $6.0^{\circ}$ ATDC onwards. The decrease of flame temperature below 2200K would suggest that combustion is taking place out of the NOx formation temperature region. This strategy had a NOx emissions value of $50 \mathrm{ppm}$, which equals to 15\% less than strategy A1. The main drawback for this strategy was the soot production as it could be expected from the lower temperature combustion. From the images of KL, it shows that from $4.8^{\circ}$ ATDC soot is produced evenly inside the cylinder, and from $7.2^{\circ}$ ATDC when the temperature has dropped the concentration of soot is higher. During the last stages of combustion, the KL factor is still high as the soot oxidation is low due to the lower temperatures. Soot emissions given in FSN can be seen in Figure 2; strategy A3 has a value of 2.25 FSN which corresponds to an increase of 60\% with respect to A1.

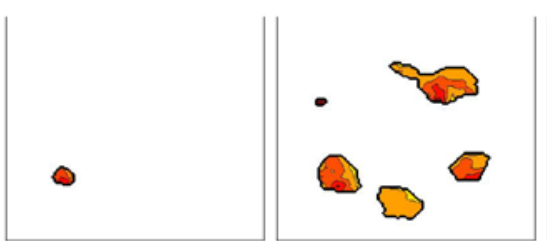

TDC

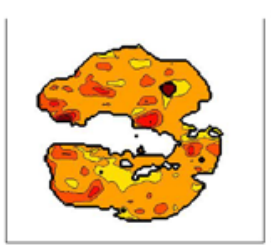

7.2 ATDC

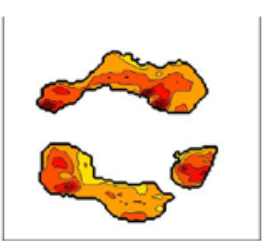

2.4 ATDC

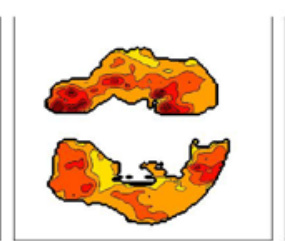

3.6 ATDC

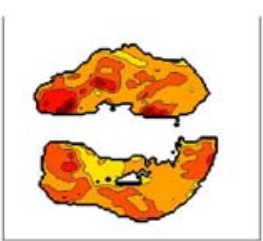

4.8 ATDC

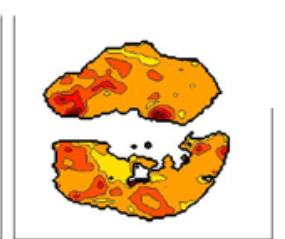

6.0 ATDC

Flame Temperature (K)
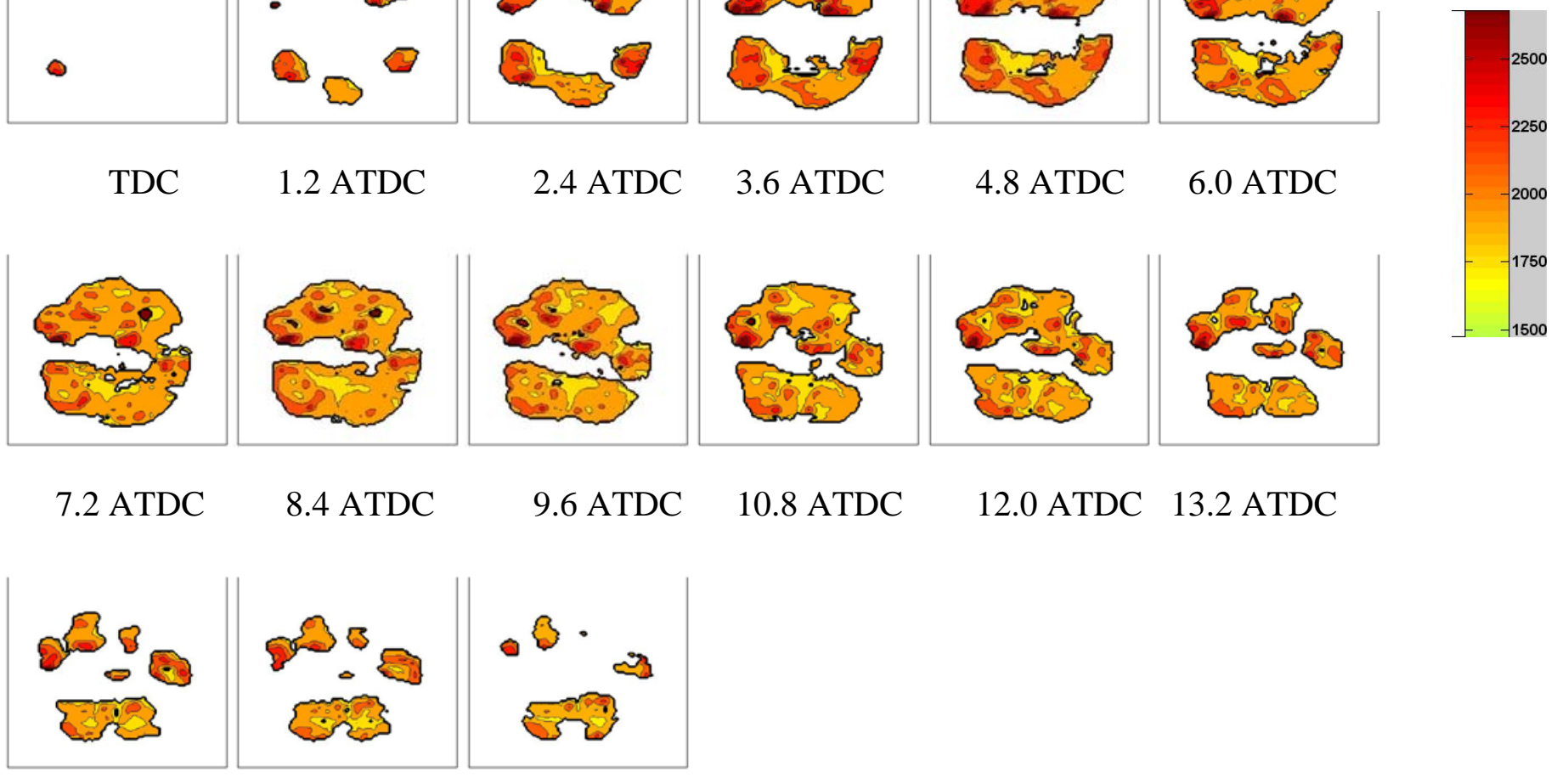

14.4 ATDC 15.6 ATDC 16.8 ATDC

Figure 9 Flame Temperature for A3, frames from TDC to 16.8 ATDC

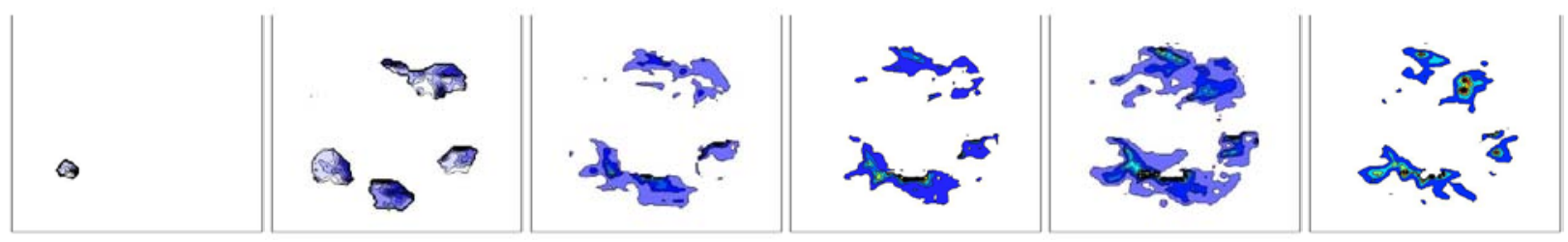

Page 11 of 16 
TDC $\quad$ 2.2 ATDC ATDC $\quad 3.6$ ATDC $\quad 4.8$ ATDC $\quad 6.0$ ATDC

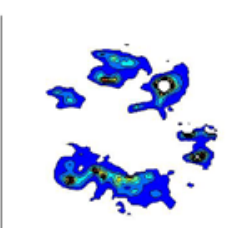

7.2 ATDC

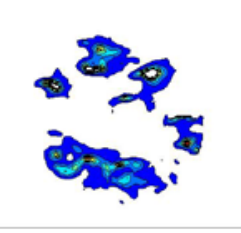

8.4 ATDC

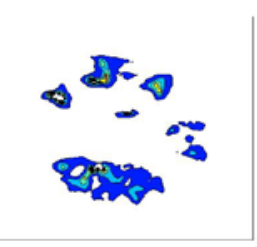

9.6 ATDC

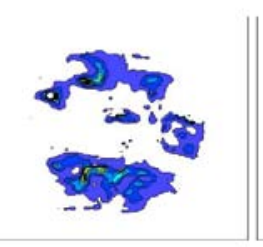

10.8 ATDC

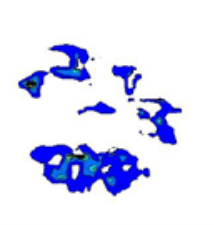

12.0 ATDC

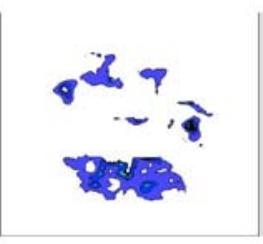

13.2 ATDC
KL Factor

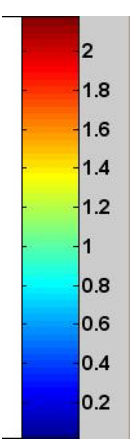

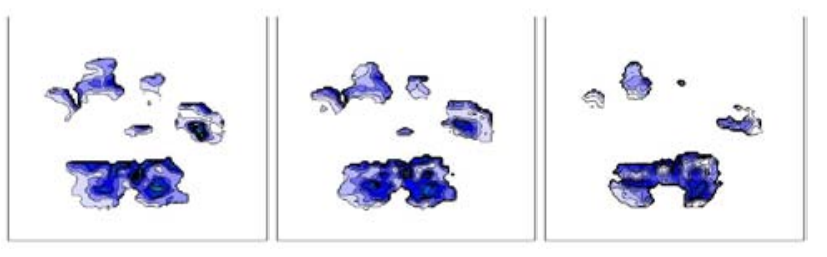

\subsection{ATDC 15.6 ATDC 16.8 ATDC}

Figure 10 KL Factor for A3, frames from TDC to 16.8 ATDC

\section{Injection Timing A5}

From the heat release rate, the start of combustion is at $3.6^{\circ} \mathrm{CA}$ ATDC; however from Figure 11 the first luminous flames appear at 5.6 $6^{\circ} \mathrm{CA}$ ATDC. Six flame spots appear uniformly distributed following the swirling motion. From frame $8.0^{\circ} \mathrm{CA}$ ATDC; it can be seen that the six flame spots spreads towards the centre of the cylinder. For this injection timing, SOI occurs only $3^{\circ} \mathrm{CA}$ after the end of the second injection and as a consequence richer diffusion combustion occurs. The ignition delay for this strategy is $14.6^{\circ} \mathrm{CA}$, compared to $15^{\circ} \mathrm{CA}$ for $\mathrm{A} 3$ and 16.4 for A1. As the ignition delay is less, the fuel has less time to mix with the air and richer combustion occurs. From frame $15.6^{\circ}$ CA ATDC the diffusion combustion is of low intensity and decreasing, but it fills the entire cylinder.

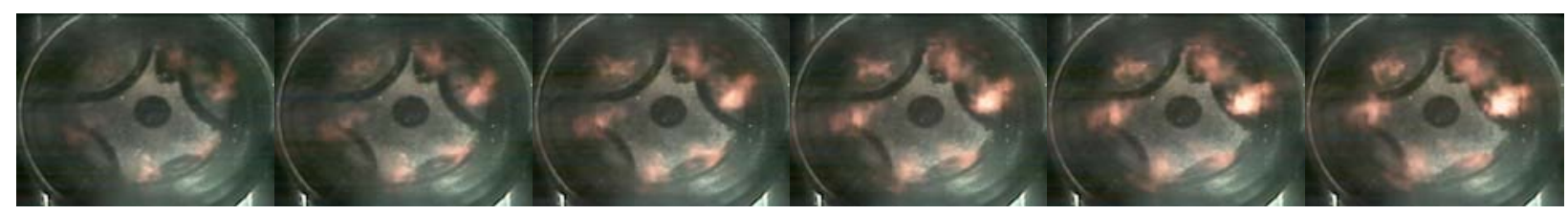
5.6 ATDC
6.8 ATDC
8.0 ATDC
9.2 ATDC
10.4 ATDC
11.6 ATDC

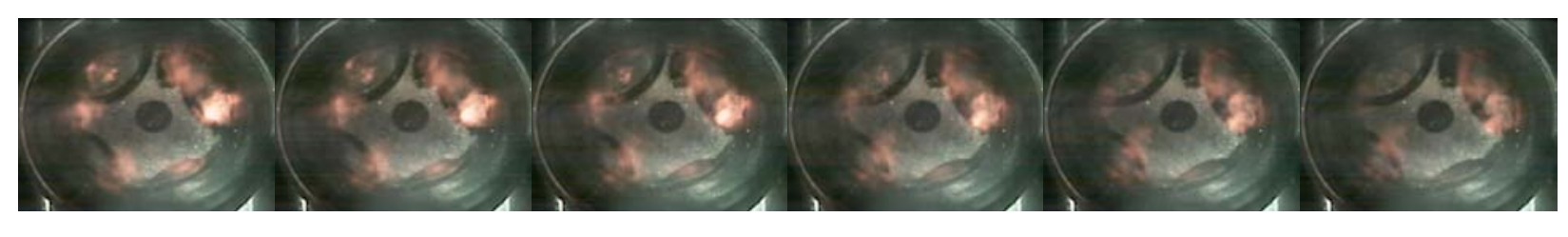
12.8 ATDC
14.0 ATDC
15.2 ATDC
16.4 ATDC
17.6 ATDC
18.8 ATDC

Page 12 of 16 


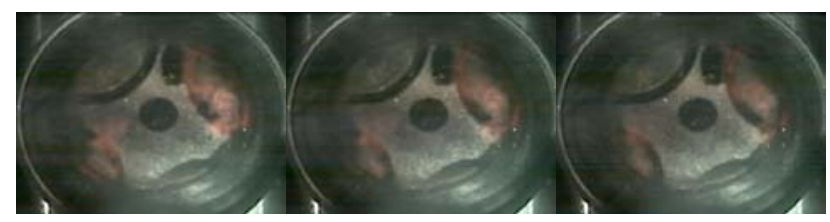

\subsection{ATDC 21.2 ATDC 22.4 ATDC}

Figure 11 Combustion Imaging for A5, frames from 5.6 ATDC to 22.4 ATDC

Figure 12 and 13 show the flame temperature and KL factor images sequence for experiment A5. From the first frames (6.8 and $8.0^{\circ} \mathrm{CA}$ ATDC) it can be seen that the flame temperature is quite well distributed inside the cylinder, surrounding the injection spray. The temperatures shown at this stage are not very high, approximately $2300 \mathrm{~K}$, and from $9.2^{\circ} \mathrm{CA}$ ATDC onwards clearly lower than this which indicates that combustion takes places out of the temperature region where NOx is normally formed. Figure 2 shows the value of NOx emissions for this strategy is $43 \mathrm{ppm}$, a reduction of $30 \%$ with respect to strategy A1. As it was shown in the combustion images, the flame temperature propagates towards the centre of the cylinder, thus frame $10.4^{\circ} \mathrm{CA}$ ATDC shows the flame temperature covering almost the whole of the chamber. As a consequence of the shorter ignition delay and lower combustion temperatures, the soot formation is much higher than for the rest of the experiments in strategy A as shown by the soot images from frame $5.6^{\circ} \mathrm{CA}$ ATDC to frame $10.4^{\circ} \mathrm{CA}$ ATDC. From frame $11.6^{\circ} \mathrm{CA}$ ATDC the KL factor appears even higher as soot oxidation rate reduces due to the lower temperatures. The final value of smoke emissions for this strategy from Figure 2 is 2.67 (FSN) which represents an increase of $100 \%$ with respect to A1.

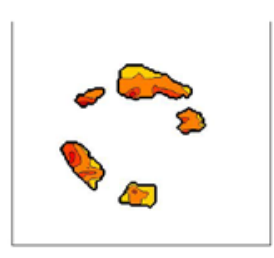

5.6 ATDC

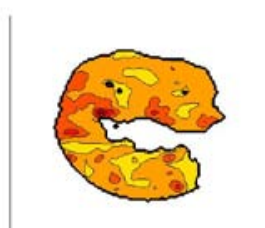

12.8 ATDC

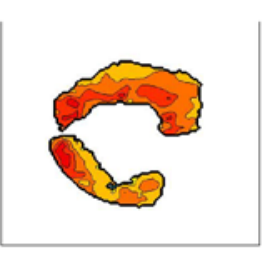

6.8 ATDC

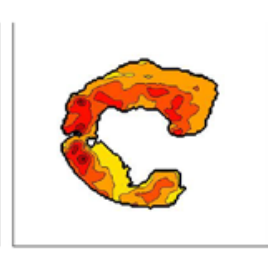

8.0 ATDC

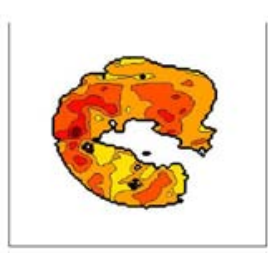

9.2 ATDC

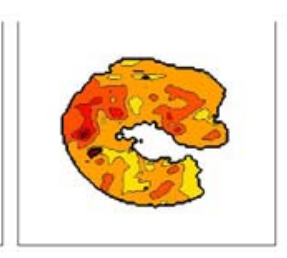

10.4 ATDC

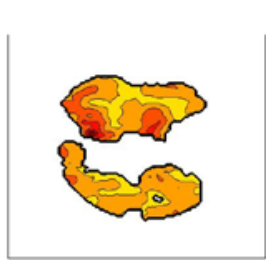

16.4 ATDC

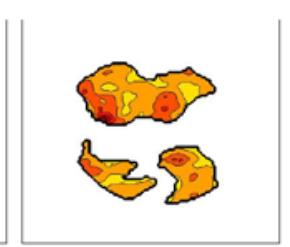

17.6 ATDC

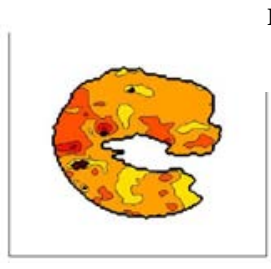

11.6 ATDC

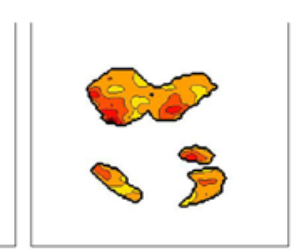

18.8 ATDC

Flame Temperature (K)

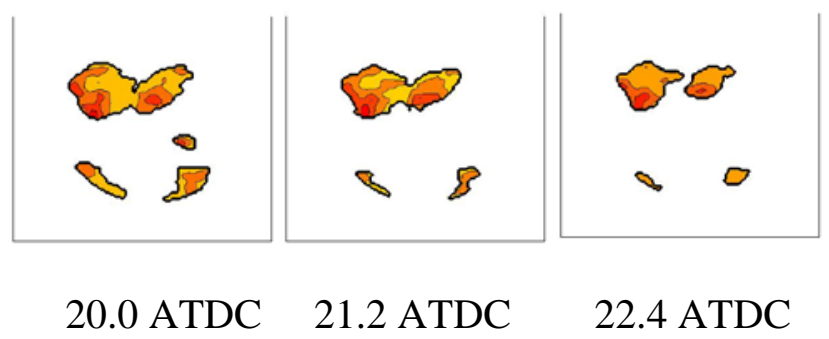

Page 13 of 16 
Figure 12 Flame Temperature for A5, frames from 5.6 ATDC to 22.4 ATDC

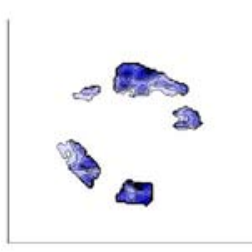

5.6 ATDC
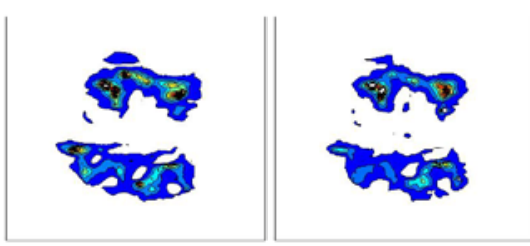

12.8 ATDC
6.8 ATDC

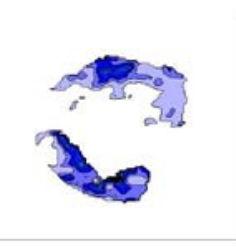

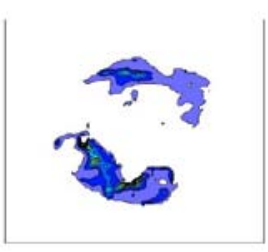

8.0 ATDC

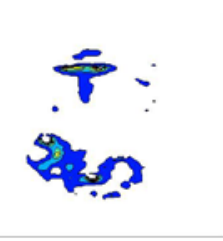

9.2 ATDC

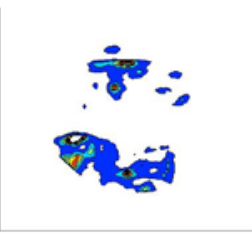

10.4 ATDC

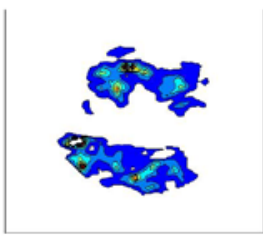

KL Factor
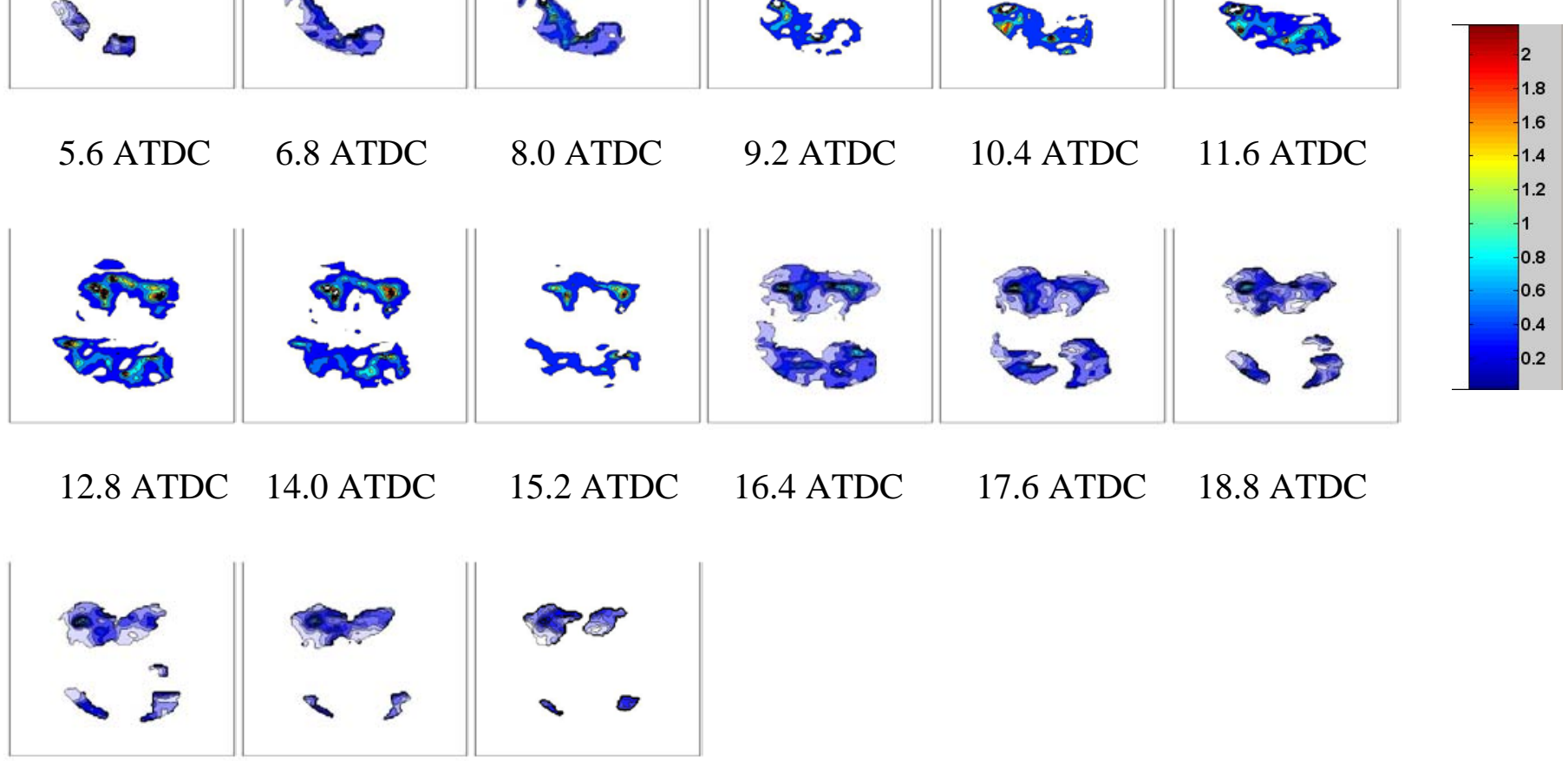

20.0 ATDC 21.2 ATDC 22.4 ATDC

Figure 13 Factor for A5, frames from 5.6 ATDC to 22.4 ATDC

\section{CONCLUSIONS}

From this study, the following conclusions can be reached regarding split injections at 1200 bar with $8^{\circ} \mathrm{CA}$ dwell angle at 2000rpm.

- Strategy A shows good IMEP and low NOx emissions. However due to the short time between injections the fuel/air mixing is poor, leading to high uHC emissions. This can be seen in the high speed combustion imaging where six flame spots spread following the swirl motion. The movies show high luminosity flames characteristic of fuel rich mixture. The other major drawback related to poor mixing is the high soot emissions. Combustion in the diffusion phase involves a rich mixture which causes high soot production while the flame temperature is not high enough to oxidise most of it. This has been noticed in the flame temperature and soot concentrations measurements given by the two colour method. As injection timing is retarded the ignition delay is shorter and therefore the in-cylinder temperatures lower. The NOx are reduced but soot emissions are higher.

\section{REFERENCES}

1. Najt, P. M. and Foster, D. E. “Compression-Ignited Homogeneous Charge Combustion”, SAE 830264, 1983.

Page 14 of 16 
2. Y. Takeda, N. Keiichi, "Emissions Characteristics of Premixed Lean Diesel Combustion with Extremely Early Staged Fuel Injection”, SAE 961163, 1996

3. Gary D. Neely, Shizuo Sasaki, Yiqun Huang, Jeffrey A. Leet and Daniel W. Stewart, "New Diesel Emission Control Strategy to Meet US Tier 2 Emissions Regulations”, SAE 2005-01-1091, 2005.

4. T. C. Tow, D. A. Pierpont, R. D. Reitz, "Reducing Particulate and NOdx Emissions by Using Multiple Injections in a Heavy; Duty D.I. Diesel Engine”, SAE 940897, 1994.

5. D. A. Nehmer, R. D. Reitz, "Measurement of the Effect of Injection Rate and Split Injections on Diesel Engine Soot and NOx Emissions”, SAE 940668, 1994.

6. Toshitaka Minami, Kouichi Takeuchi, Naoki Shimazaki, "Reduction of Diesel Engine NOx Using Pilot Injection”, SAE 950611, 1995.

7. D. A. Pierpont, D. T. Montgomery, R. D. Reitz, "Reducing Particulate and NOdx Using Multiple Injections and EGR in a D.I. Diesel”, SAE 950217, 1995.

8. Zhiyu Han, Ali Uludogan, Gregory J. Hampson, Rolf D. Reitz, "Mechanism of Soot and NOx Emission Reduction Using Multiple-Injection in a Diesel Engine”, SAE 960633, 1996.

9. P. V. Farrell, C. T. Chang, T. F. Su, “High Pressure Multiple Injection Spray Characteristics”, SAE 960860, 1996.

10. D. T. Montgomery and R. D. Reitz, "Effects of Multiple Injections and Flexible Control of Boost and EGR on Emissions and Fuel Consumption of a Heavy-Duty Diesel Engine”, SAE 2001-01-0195, 2001.

11. P. J. Shayler, T. D. Brooks, G. J. Pugh and R. Gambrill, "The Influence of Pilot and Split-Main Injection Parameters on Diesel Emissions and Fuel Consumption”, SAE 2005-01-0375, 2005.

12. Yuyin Zhang, Tomoaki Ito and Keiya Nishida, "Characterization of Mixture Formation in Split-Injection Diesel Sprays via Laser Absorption-Scattering (LAS) Technique”, SAE 2001-01-3498, 2001.

13. Yuyin Zhang and Keiya Nishida, "Vapor/Liquid Behavior in Split Injection D.I. Diesel Engine Sprays in a 2-D Model Combustion Chamber”, SAE 2003-01-1837, 2003.

14. Marco Bakenhus, Rolf D. Reitz, “Two-Colour Combustion Visualization of Single and Split Injections in a Single-Cylinder, Heavy-Duty D.I. Diesel Engine Using an Endoscope-Based Imaging System”, SAE 199901-1112, 1999.

15. S. Kevin Chen, "Simultaneous Reduction of NOx and Particulate Emissions by Using Multiple Injections in a Small Diesel Engine”, SAE 2000-01-3084, 2000.

16. C. Beatrice, P. Belardini, C. Bertoli, N. Del Giacomo, Ma. Migliaccio, "Downsizing of Common-Rail D.I. Engines: Influence of Different Injection Strategies on Combustion Evolution”, SAE 2003-01-1784, 2003.

17. Yi Liu and Rolf D. Reitz, “Optimizing HSDI Diesel Combustion and Emissions Using Multiple Injection Strategies”, SAE 2005-01-0212, 2005.

18. K. Gill and H. Zhao, "In-cylinder Studies of Fuel Injection and Combustion from a Narrow Cone Fuel Injector in a High Speed Single Cylinder Optical Engine”, SAE 2008-01-1789, 2008.

19. Tobias Husberg, Ingemar Denbratt and Anders Karlsson, “Analysis of Advanced Multiple Injection Strategies in a Heavy-Duty Diesel Engine using Optical Measurements and CFD-Simulations”, SAE 200801-1328, 2008.

20. Zhao H. and Ladommatos N., "Engine Combustion Instrumentation and Diagnostics”, Society of Automotive Engineers, Inc., 2001.

21. J. V. Pastor, J. M. Garclaia, J. E. Buitrago, “Analysis Methodology of Diesel Combustion by Using Flame Luminosity, Two-Colour Method and Laser-Induced Incandescence”, SAE 2005- 24-012, 2005.

22. F Payri, J V Pastor, J M García and J M Pastor., "Contribution to the application of two-colour imaging to diesel combustion”, Measurement Science and Technology, Vol. 18, 2007. 


\section{CONTACT INFORMATION}

Alvaro Diez, a.diez@qmul.ac.uk

Page 16 of 16 